University of Nebraska - Lincoln

DigitalCommons@University of Nebraska - Lincoln

Faculty Publications from the Department of Electrical \& Computer Engineering, Department Electrical and Computer Engineering

2000

\title{
Class Project on Airborne Radar System Design and Development for Remote Sensing Applications
}

\author{
Ram M. Narayanan \\ University of Nebraska-Lincoln \\ K. Jon Ranson \\ University of Nebraska-Lincoln
}

Follow this and additional works at: https://digitalcommons.unl.edu/electricalengineeringfacpub

Part of the Electrical and Computer Engineering Commons

\begin{abstract}
Narayanan, Ram M. and Ranson, K. Jon, "Class Project on Airborne Radar System Design and Development for Remote Sensing Applications" (2000). Faculty Publications from the Department of Electrical and Computer Engineering. 146.

https://digitalcommons.unl.edu/electricalengineeringfacpub/146
\end{abstract}

This Article is brought to you for free and open access by the Electrical \& Computer Engineering, Department of at DigitalCommons@University of Nebraska - Lincoln. It has been accepted for inclusion in Faculty Publications from the Department of Electrical and Computer Engineering by an authorized administrator of DigitalCommons@University of Nebraska - Lincoln. 


\title{
Class Project on Airborne Radar System Design and Development for Remote Sensing Applications
}

\author{
Ram M. Narayanan ${ }^{\star}$ and K. Jon Ranson ${ }^{\dagger}$ \\ ${ }^{\star}$ Department of Electrical Engineering and Center for Electro-Optics \\ University of Nebraska, Lincoln, NE 68588-0511, USA \\ T: $402.472 .5141 \quad$ F: $402.472 .4732 \quad$ EMail: rnarayanan@unl.edu \\ ${ }^{\dagger}$ Biospheric Sciences Branch, Code 923 \\ NASA Goddard Space Flight Center, Greenbelt, MD 20771, U.S.A. \\ T: $301.614 .6650 \quad$ F: $301.614 .6695 \quad$ EMail: jon.ranson@gsfc.nasa.gov
}

\begin{abstract}
A unique experiment on remote sensing education has recently been undertaken involving an educational institution (University of Nebraska-Lincoln) and a government agency involved in remote sensing (NASA Goddard Space Flight Center). The centerpiece of this experiment is the assignment of an airborne radar system design project to students enrolled in a senior undergraduate and graduate level class on Radar Systems. The class was split into two competing teams. A fictitious request for proposal (RFP) was issued by NASA GSFC, and the teams responded to the RFP by proposing and defending competing designs. The teams also prepared final design reports, and made oral presentations on their designs during the final examination week. Individual and team scores assigned to each student was included in his/her overall grade for the course. Our experience shows that this technique was very successful, and the students came up with excellent designs. It also provided students with an opportunity for enhancing team work, addressing multidisciplinary science aspects, perfecting technical writing and presentation skills, and responding to agency RFPs.
\end{abstract}

\section{RADAR SYSTEM COURSE DESCRIPTION}

The University of Nebraska-Lincoln (UNL) offers the course ELEC 483/883 on Radar Systems every two years during the 15-week Fall semester. The purpose of this course is to introduce senior undergraduate and graduate students to the design and application of various types of radar systems, with emphasis on practical problems associated with system design. The course content includes a radar design project which is intended to provide the students with real-world team-effort and goal-oriented experience. Topics covered in the course include radar range equation derivation, radar phenomenology, radar sub-assemblies, detection and clutter, radar system architectures, radar applications, and electronic countermeasures. The text used in the course is Introduction to Radar Systems (2nd Ed.) by Merrill I. Skolnik. Handouts from articles in trade and professional journals such as Microwave Journal, IEEE Transactions on Microwave Theory and Techniques, IEEE Transactions on Antennas and Propagation, and IEEE Transactions on Geoscience and Remote Sensing are also provided to the students.

Although the course is primarily meant for electrical engineering students, it is also taken by a few students from other departments interested in remote sensing. On an average, the number of students in each semester is between 8 and 12. For the radar design project, the class is typically split into two or three project teams of 4-6 students each, who compete for a fictitious "contract." The radar design project accounts for $40 \%$ of the total course grade, with $20 \%$ allocated to team performance (same for all members of a team) and $20 \%$ allocated to individual effort. The remaining $60 \%$ of the course grade is allocated to mid-term tests and homework.

\section{RADAR PROJECT ASSIGNMENT AND EVALUATION}

Students are assigned to each team by the instructor in such a manner as to balance their technical backgrounds, interests, and personalities. During the fourth week of the course, a suitable project is assigned in consultation with technical personnel from external organizations [1]. The project for Fall 1999 was assigned by a NASA scientist, who agreed to serve as the Project Monitor. The following project was assigned:

NASA has a need for an airborne radar system for use in resource monitoring and hydrological studies. The system, to be flown at a height of $3,500 \mathrm{me}$ ters, will be required to simultaneously estimate tree height, above ground biomass, and underlying soil moisture beneath the canopy. The required measurement accuracies are 1 meter for tree height, 10\% for biomass (within the range 2-40 kilograms per square meter), and 5\% for soil moisture. The required spatial resolution is 3 meters, and the swath width must be at least 5 kilometers.

The teams, led by their elected group leaders, scheduled weekly meetings to review assigned tasks. Individual tasks were assigned to each student after extensive discussions between team members. The group leaders also periodically consolidated questions and sought clarifications from the instructor and the project monitor. Constant interaction between the teams and the NASA monitor resulted in better understanding of the design constraints by the teams, thereby helping them sharpen their designs and contributing to the learning experience of the team members. The students were encouraged to specify commercially-off-the shelf(COTS) components, as far as possible, to ensure a low-cosi design. The widespread availability of the internet also provided an extensive resource base for the project.

The approach followed by Team A was a dual-frequency ( $P$ and $\mathrm{L}$ band) chirp-SAR technique. The operating frequencies were $440 \mathrm{MHz}$ and $1.22 \mathrm{GHz}$, and their choice was motivated 
by the availability of radar backscatter coefficient data on vegetation at these frequencies. The pulse width was chosen as 100 nsec with a chirp bandwidth of $100 \mathrm{MHz}$. The transmit power used was $2 \mathrm{~W}$ at $\mathrm{P}$ band and $20 \mathrm{~W}$ at $\mathrm{L}$ band, while the receiver front-end noise figure was $1.4 \mathrm{~dB}$ max. at $\mathrm{P}$ band and 1.5 $\mathrm{dB}$ max. at $\mathrm{L}$ band. All four polarization combinations (VV, $\mathrm{VH}, \mathrm{HH}, \mathrm{HV}$ ) were used. The radar depression angle of $40 \mathrm{de}-$ grees was chosen to maximize the sensitivity to soil moisture, while maintaining the required swath width. This choice of depression angle provided the slant-range resolution of $3 \mathrm{~m}$. The choice of a dual-polarized circular microstrip array antenna, one for transmit and one for receive, was motivated by the need to minimize weight and maintain a low profile for aerodynamic reasons. Since these antennas are typically narrowband devices (15\% bandwidth), two such antenna pairs were used, one for each frequency. For a minimum normalized radar cross section (NRCS) value of $-20 \mathrm{~dB}$ for the radar system parameters as described above, a signal-to-noise ratio (SNR) of at least $26 \mathrm{~dB}$ was computed. System simulations were performed to demonstrate the resolution capabilities of the designed system, as well as accuracies in soil moisture, biomass, and tree height estimation using existing or empirically-developed models. The issue of calibration was also addressed.

Team B followed a dual-frequency ( $L$ and $X$ band) steppedfrequency SAR approach. The operating frequencies were 1.5 $\mathrm{GHz}$ and $10 \mathrm{GHz}$. The low frequency was chosen for soil moisture estimation, while the high frequency was chosen for biomass estimation. Each pulse at each frequency step had a duration of $765 \mathrm{nsec}$, and the total number of pulses in each burst, i.e. number of frequency steps, was chosen as 42 . With each frequency step being $1.3 \mathrm{MHz}$, the total bandwidth was $54.6 \mathrm{MHz}$. With an incidence angle of 58 degrees, a 3-m slant range resolution was achieved. The transmit power was $2.4 \mathrm{~W}$ at $\mathrm{L}$ band, and $7 \mathrm{~W}$ at $\mathrm{X}$ band, while the receiver noise figures were $2.2 \mathrm{~dB}$ max. and $3.5 \mathrm{~dB}$ max. at $\mathrm{L}$ and $\mathrm{X}$ bands respectively. The antenna selected was a parabolic reflector of $70-\mathrm{cm}$ diameter, fed by a wideband $(1-18 \mathrm{GHz})$ dual-polarized log-periodic antenna placed at its focus. Two antennas, one for transmit and one for receive were used. Simulations were performed to satisfy resolution considerations, as well as to estimate accuracies in soil moisture, biomass, and tree height estimation.

A preliminary design report was provided to the instructor and the project monitor at the end of the 13th week. These were critically reviewed, and comments forwarded to the teams for redressal of weak points in the design. After comments and criticisms were addressed, a final design report was provided and a final project presentation was made during the final examination week. The formal professional presentation was made to an audience consisting of the instructor, faculty members, and graduate students.

Each group leader presented an overview of the overall design first, followed by individual members describing their separate contributions. Students fielded wide-ranging questions from the audience. The external project monitor perused the final report and provided his assessment of each design, which was used in assigning overall points for each individual. Other factors that influenced the project grade were: (1) technical effort, (2) thoroughness of research, (3) quality of technical report, (4) clarity of technical presentations, (5) response to audience questions, and (5) overall group effort.

\section{CONCLUSIONS}

Our experience shows that this technique was very successful, and the students came up with excellent designs. It also provided students with an opportunity for enhancing team work, addressing multidisciplinary science aspects, working with members of varying technical backgrounds and research interests, perfecting technical writing and presentation skills, and responding to agency RFPs. Although the time and effort expended by the students were much more than for a comparable 3-credit course, it was felt that the students benefitted greatly from the project.

\section{ACKNOWLEDGMENTS}

The students who participated in the course during the Fall 1999 semester were: E. Borissov, P. Crittenden, D. Garmatyuk, J. Fernandez, E. Penne, M. Smith, and W. Leon Salas from the Electrical Engineering Department, and H. Bulley and J. Hlady from the School of Natural Resource Studies. Their enthusiasm and hard work are very much appreciated.

\section{DISCLAIMER}

NASA's participation in this experiment is purely on a voluntary basis. NASA endorsement of the design projects is neither expressed nor implied.

\section{REFERENCES}

[1] R.M. Narayanan, J. Holt, and E. Abel, "A project-oriented radar systems course: a novel experiment in cooperative pedagogy," International Journal of Electrical Engineering Education, Vol. 29, No. 1, pp. 42-46, January 1992. 